\title{
Evaluation of high definition digital video signal over coaxial transmission lines
}

\author{
*R. Fernández-García and I. Gil \\ Department of Electronic Engineering, Universitat Politècnica de Catalunya \\ 08222 Colom 1, Terrassa, Spain. *E-mail: raul.fernandez-garcia@upc.edu
}

\begin{abstract}
In this paper, the propagation of two different digital video transmission standards have been evaluated over fifteen different coaxial cables. The frequency dependence of the attenuation for each cable and the maximum cable length for each standard have been obtained. The results show that the propagation properties improve with the inner conductor thickness and it is better to use coaxial cable with an inner conductor based on several filaments.
\end{abstract}

\section{INTRODUCTION}

The Society of Motion Picture and Television Engineers (SMPTE) defined the SMPTE292 and SMPTE424M to transmit high definition digital video and audio over coaxial cables at 1.485 Gbits/s [1] and 2.970 Gbits/s [2], respectively. In both cases, the amplitude of the signal should be between $720 \mathrm{mV}$ and $880 \mathrm{mV}(800 \mathrm{mV} \pm 10 \%)$, the rise/fall time and unit intervals are $270 \mathrm{ps}$ and 673.4 ps for SMPTE292. In case of SMPTE424 these values are reduced to 135 ps and $336.7 \mathrm{ps}$, respectively. On the one hand, these signal requirements require good conductors to guarantee the correct level of video transmission. On the other hand, the current cooper price has increased the cost of coaxial cables and, thus, a trade-off between the quality of connections and the cost of the installation appears. Therefore, in order to select the correct transmission line for one particular installation, an analysis of signal quality / installation cost should be done. In this work, the high definition video signal transmission has been evaluated for several coaxial transmission lines with the aim to determine the optimum cable configuration for specific installations. The remainder of the paper is organised as follows. Section 2 describes the cables under test and the measurement procedure. In Section 3 the experimental results are shown and discussed. Finally, in Section 4 the main conclusions are drawn.

\section{MATERIALS AND METHODS}

\subsection{Cables under test}

In this work, fifteen different coaxial cables have been evaluated: eight coaxial cables with rigid inner conductor and seven with flexible inner conductor. In all cases the inner conductors are oxygen-free copper (OFC), the dielectric materials are foam high density polyethylene (FHDPE) and the jacket materials are Polyvinyl Chloride (PVC). Table 1 and Table 2 summarize the properties of rigid and flexible coaxial cables under test, respectively. 
Table 1. Properties of rigid coaxial cables under test

\begin{tabular}{|c|c|c|c|c|c|}
\hline Cable & $\begin{array}{c}\text { \# Inner conductors } \\
\text { /diameter (mm) }\end{array}$ & AWG & Outside dielectric diameter (mm) & Shield & Jacket diameter (mm) \\
\hline $\mathbf{1 R}$ & $1 / 0.41$ & 26 & 1,9 & Foil \& Braid & 3,5 \\
\hline $\mathbf{2 R}$ & $1 / 0.51$ & 24 & 2,40 & Foil \& Braid & 3,81 \\
\hline $\mathbf{3 R}$ & $1 / 0.584$ & 23 & 2,77 & Foil \& Braid & 4,5 \\
\hline $\mathbf{4 R}$ & $1 / 0.80$ & 20 & 3,75 & Foil \& Braid & 6,0 \\
\hline $\mathbf{5 R}$ & $1 / 1.00$ & 18 & 4,60 & Foil \& Braid & 7 \\
\hline $\mathbf{6 R}$ & $1 / 1.40$ & 15 & 6,60 & Foil \& Braid & 9,2 \\
\hline $\mathbf{7 R}$ & $1 / 1.60$ & 14 & 7,10 & Foil \& Braid & 10,3 \\
\hline $\mathbf{8 R}$ & $1 / 2.05$ & 14 & 8,20 & Foil \& Braid & 11,1 \\
\hline
\end{tabular}

Table 2. Properties of flexible coaxial cables under test

\begin{tabular}{|c|c|c|c|c|c|}
\hline Cable & $\begin{array}{l}\text { \# Inner conductors } \\
\text { /diameter (mm) }\end{array}$ & AWG & Outside dielectric diameter (mm) & Shield & $\begin{array}{c}\text { Jacket } \\
\text { diameter } \\
(\mathbf{m m})\end{array}$ \\
\hline $1 F$ & $7 / 0,10$ & 30 & 1,5 & Spiral & 2,8 \\
\hline $2 \mathbf{F}$ & $19 / 0,10$ & 26 & 2,55 & Braid & 4,3 \\
\hline $3 \mathbf{F}$ & $7 / 0,254$ & 22 & 3,4 & Braid & 6,0 \\
\hline $4 F$ & $19 / 0,20$ & 20 & 4,2 & Double Braid & 6,20 \\
\hline $5 F$ & $80 / 0,10$ & 20 & 4,9 & Foil \& Braid & 8,0 \\
\hline $6 F$ & $7 / 0,40$ & 18 & 5,0 & $\begin{array}{l}\text { Double Foil } \\
\& \text { Braid }\end{array}$ & 7,0 \\
\hline $7 F$ & $19 / 0,254$ & 18 & 5,2 & Double Braid & 7,20 \\
\hline
\end{tabular}

\subsection{Experimental setup}

Each cable has been subjected to two different tests. On the one hand, the frequency responses of each cable have been simulated in order to obtain the attenuation and the maximum cable length for one specific digital video standard. On the other hand, the maximum cable length has been experimentally evaluated with a video signal generator DeckLink Studio $4 K$ and a Tektronix WVR8200 video analyser, as it is shown in Fig. 1.

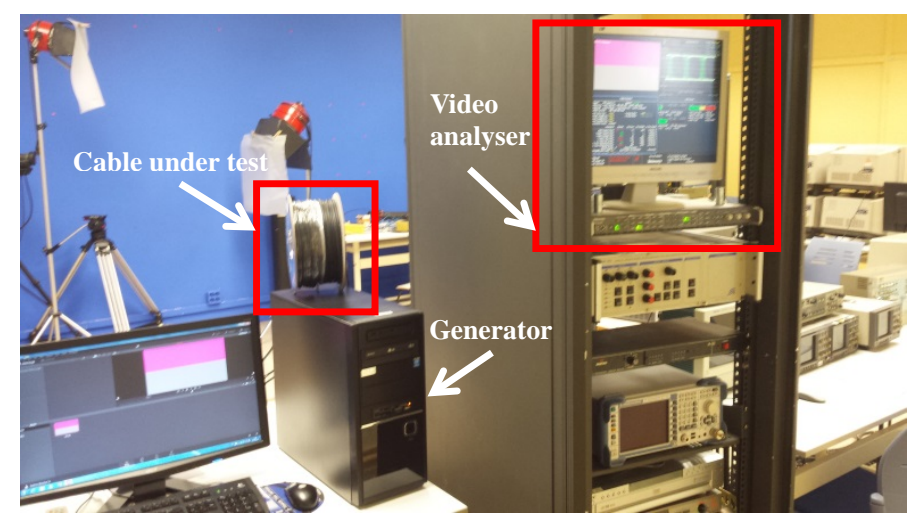

Fig. 1. Experimental setup to evaluate the maximum cable length of digital video. 


\section{RESULTS AND DISCUSSION}

Fig. 2 shows the frequency dependence of the attenuation for a cable length of $100 \mathrm{~m}$. It is observed that the attenuation increases with the frequency, as expected. At the same frequency, higher attenuation value is obtained for thinner cables. For instance, at $1 \mathrm{GHz}$ the attenuation for the thinner rigid cable (R1) reached $50 \mathrm{~dB}$ whereas the attenuation for thicker rigid cable (R8) is about $11 \mathrm{~dB}$. For similar American Wire Gauge (AWG), the attenuation is lower in flexible coaxial cables. As an example, at $1 \mathrm{GHz}$ and AWG of 26 the attenuation of rigid cable (cable $\mathrm{R} 1$ ) it is $50 \mathrm{~dB}$ meanwhile this value decreases at $40 \mathrm{~dB}$ for flexible cable (cable F2). The flexible cable inner conductor is composed of several filaments and, therefore the lower attenuation on flexible cables can be due to the lower impact of skin effect.

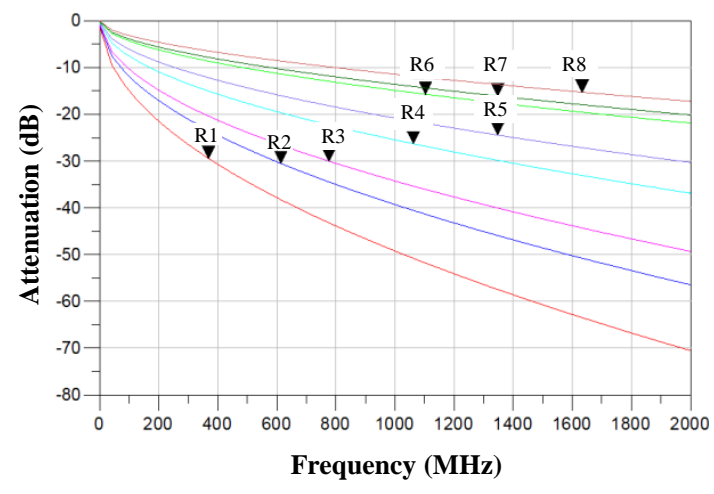

a)

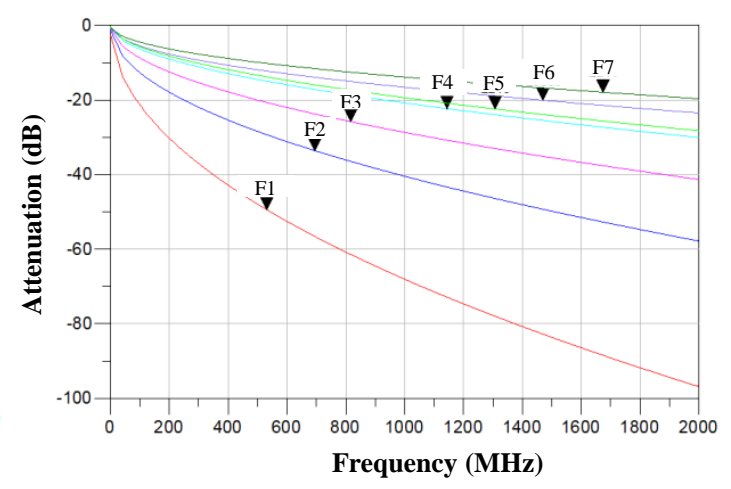

b)

Fig. 2. Attenuation frequency responses for a cable length of $100 \mathrm{~m}$. a) rigid cables, b) flexible cables.

Fig. 3 compares the dependence of the attenuation with the cable length (for rigid and flexible coaxial cables) and two different digital video transmission standards; SMPTE 292m and SMPTE $424 \mathrm{~m}$, with a bit-rate $1.485 \mathrm{Gbps}$ and $2.970 \mathrm{Gbps}$, respectively. For the same attenuation (i.e. $20 \mathrm{~dB}$ ), the maximum cable length is higher for ticker cables in all cases. The maximum cable length increases from $48 \mathrm{~m}$ for cable R1 to $198 \mathrm{~m}$ for cable R8 for SMPTE $292 \mathrm{~m}$ and from $33 \mathrm{~m}$ to $137 \mathrm{~m}$ for SMPTE $424 \mathrm{~m}$. For similar gauge and attenuation, better performance is achieved for flexible cables. For instance, for SMPTE292 standard, AWG 26 and $20 \mathrm{~dB}$ attenuation, the cable length increases from $48 \mathrm{~m}$ to $58 \mathrm{~m}$ for cable R1 and cable F2 respectively. For SMPTE $424 \mathrm{~m}$ standard (attenuation 20dB), the cable length values move from $33 \mathrm{~m}$ (cable R1) to $40 \mathrm{~m}$ (Cable F2). The SMPTE 292m and SMPTE 424m define that the typical loss amount which would be in the range of up to $20 \mathrm{~dB}$ at one-half of the clock frequency. Taking into account this reference, it is possible to predict the maximum length for one specific cable and standard. Table 3 summarizes the maximum coaxial length for the fifteen cables under test and the two standards under investigation. 


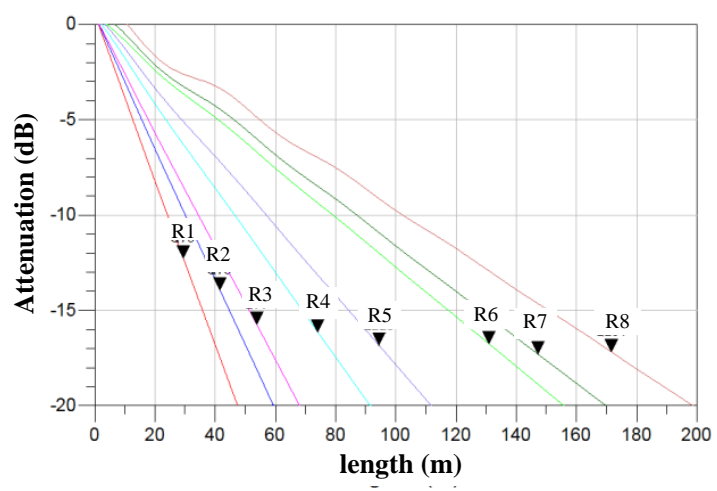

b) SMPTE 292m rigid cables

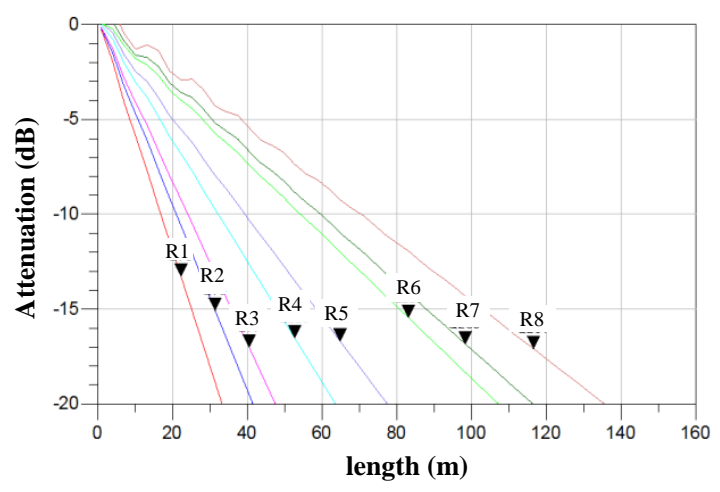

d) SMPTE $424 \mathrm{~m}$ rigid cables

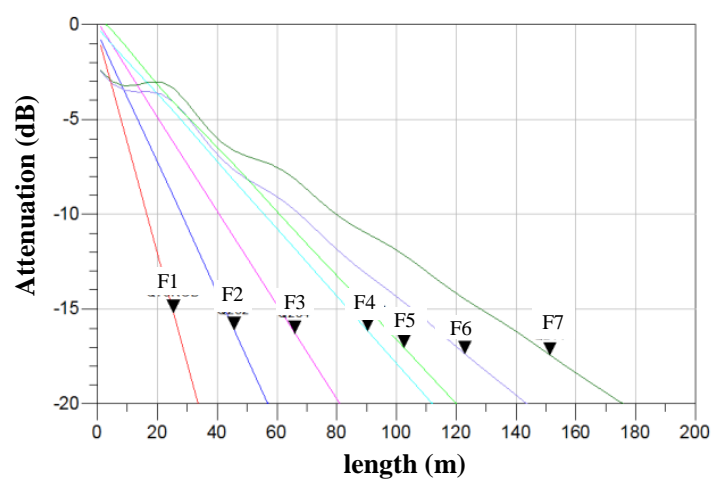

a) SMPTE 292m flexible cables

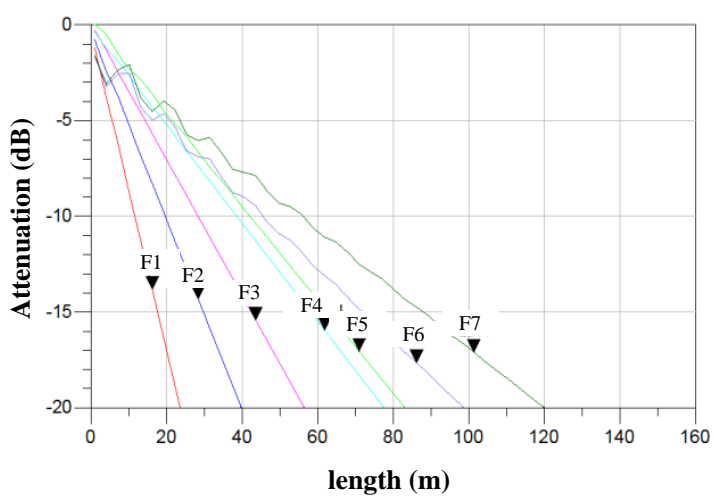

c) SMPTE $424 \mathrm{~m}$ flexible cables

Fig. 3. Dependence of attenuation with the cable length for two different digital video formats.

Table 3. Maximum cable length (m) in order to guarantee the high definition digital video transmission.

\begin{tabular}{|c|c|c|c|c|c|c|c|c|c|c|c|c|c|c|c|c|}
\hline & \multicolumn{15}{|c|}{ Cable } \\
\hline & & R1 & R2 & R3 & R4 & R5 & R6 & R7 & R8 & F1 & F2 & F3 & F4 & F5 & F6 & F7 \\
\hline \multirow{2}{*}{$\sum_{\infty}^{0}$} & 292M & 48 & 60 & 69 & 92 & 103 & 155 & 170 & 198 & 33 & 58 & 80 & 111 & 120 & 142 & 176 \\
\hline & $424 M$ & 33 & 41 & 48 & 62 & 78 & 109 & 118 & 137 & 22 & 40 & 56 & 78 & 82 & 100 & 120 \\
\hline
\end{tabular}

\section{CONCLUSIONS}

In this work, the maximum length of several coaxial cables to transmit a high definition digital video under the standards SMPTE 292m and SMPTE 424m had been evaluated. The results show that the maximum cable length increases with the inner conductor thickness and due to the skin effect, for similar cable gauge, it is better to use cables with inner conductor base on multifilament. Taking into account the results it is possible to determine the optimum cable type for one specific installation requirement.

\section{ACKNOWLEDGEMENT}

This work was supported by the AGAUR 2014 SGR 375. The research team would like to thank Carles Alonso for deploying the experimental setup and carrying out the measurements.

\section{REFERENCES}

[1]. $\quad 1.5 \mathrm{~Gb} / \mathrm{s}$ Signal/Data Serial Interface," in SMPTE ST 292-1:2012 , vol., no., pp.1-20, Jan. 3 2012. doi: 10.5594/SMPTE.ST292-1.2012

[2]. $3 \mathrm{~Gb} / \mathrm{s}$ Signal/Data Serial Interface," in SMPTE ST 424:2012, vol., no., pp.1-10, Oct. 8 2012.doi: 10.5594/SMPTE.ST424.2012 